\title{
A RESPONSE TO POLLUTION OF HAZARDOUS SUBSTANCES FROM SHIPS
}

\author{
Goran Bakalar ${ }^{1}$, Myriam Beatriz Baggini ${ }^{2}$, Sebastian Gabriel Bakalar ${ }^{3}$ \\ ,2,3Bonum Mare Consulting LLC, 148 Young Ave, Cocoa Beach, 32931, FL, USA
}

Received 2 October 2016; accepted 17 November 2016

\begin{abstract}
Transport of cargo and passengers has a negative influence on human and nature habitats. Pollution in air and water, with its negative impact on environment and quality of human life, was an objective in this research. Use of satellite communication technologies for sea pollution monitoring has been analyzed in this article. Satellite communication technology today, covers monitoring of oil pollutions. Technological limitations and improving potential of that kind of monitoring were listed and described. It has been researched possibility of use of monitoring potential of oil discharge monitor for monitoring of chemical pollutions from the ships. Certain cases from operational experience and registered accidents were explained in this paper. Possible reasons of the accidents were brought out after experience cases were analyzed. Chemical pollution cases were taken as good examples in this review, being compared against oil pollution cases. Minor oil pollutions in coastal area were drastically reduced since oil discharge monitor has been in use. That advantage in oil cases is being taken into consideration in this paper and another solution proposed. Proposed solution in this review is possibility of use of satellite positioning system combined with good software programs and emergency procedures already in use on the ships. In this solution satellite communication technologies would force up ship operators to work in accordance with the pollution prevention law. Automation would stop chemical pollution in coastal areas.
\end{abstract}

Keywords: liquid chemicals transportation, coastal area contamination, chemical pollution, flow cytometer, EMS.

drinking water depends on the amount of water consumed. It is usually 2 to 3 liters per day for an adult, with higher amounts for people working in hot engine rooms or people engaged in heavy physical work on the open decks. Use of contaminated water in food preparation can result in contaminated food, because high cooking temperatures do not affect the toxicity of most chemical contaminants (Chem-Tox, 2016).

Very high amounts of the fresh water produced on ships are in use on very big passenger ships. There is no sensor to detect contaminated sea water while being pumped into the desalination machinery. Inhalation exposure to volatile compounds during hot showers and skin exposure while bathing or using water for recreation is also potential routes of exposure to water pollutants. Examples of disease are the nervous system diseases of methylmercury poisoning (Minamata disease), the kidney and bone diseases of chronic cadmium poisoning (Itai-Itai disease), and the circulatory system diseases of nitrate

\footnotetext{
${ }^{1}$ Corresponding author: Goran.Bakalar@xnet.hr
} 


\section{Introduction}

The intention in this review is to explore improving possibility to prevent deliberate chemical pollution from ships in coastal area and all other protected areas. It is easier to fight oil pollution than chemical pollution, since the oil floats and doesn't dissolve in the water. The worst oil pollution accidents in history initiated international activity against all possible oil pollutions. Knowledge on the impacts of the oil spills from the Exxon Valdez (at Alaska coast 1989), Sea Empress (in Wales 1996), and Prestige (coast of Galici 2002), have resulted in the development of measures to protect the marine environment from pollution in the seas (EPA 2011.; EEA, 1998.). Existing regulatory frameworks do not address the full range of potentially damaging pollutants. Scientists have proved that, even in the open ocean, large fish sometimes contain high concentrations of mercury (Roose and Brinkman, 2005). The monitoring of seas has been largely based on the measurement of chemical concentrations in water, sediments and biota. Current programmes do not take sufficiently sophisticated approaches to prevent pollution of chemicals on individuals, populations, and ecosystems. Obligating conventions, regulations and procedures were enforced and lot of education was ordered and has been done. One of the best inventions during that activity was the implementation of oil discharge monitor. That unit, installed on the ships worldwide, prevented many oil pollutions and still does the best oil pollution control among all other preventing activities. Ship's chemical discharge monitor doesn't exist. That makes risk of chemical incidents higher, and gives more room for uncontrolled operations on the ships (Bakalar, 2011; Bakalar, 2014). There are two types of risks involved in chemical incidents which, to some extent, are independent of the type of maritime transport of the products, whether carried in bulk or in packaged form. These are risks involving the personnel (crew, intervening personnel, and the local population) and more specifically the environment. The occurrence of marine chemical pollutants has its sources of direct releases (e.g. from shipping), land-based river run-off or atmospheric deposition, all of which contribute significantly to marine pollution. The aim of this research is a specific pollution with chemicals: washing cargo tanks where the liquid chemical cargo was stowed. The washing of tanks takes place after ship's departure from a chemical cargo terminal.

\section{Materials and Methods}

Material in this research is sea water contaminated by liquid chemicals and authors suggested methods to prevent one of the pollutions that they observed during their work on ships There were many minor chemical pollutions from the ships in coastal area with different causes. Some of those pollutions were done by improper cargo handling, cargo loading or cargo discharging. Spill of chemicals into seawater may give rise to health hazards because of the contamination of fish or shellfish (Bonn Agreement, 2002). Seawater pollution with persistent chemicals, and dioxins, can also be a significant health hazard even at extremely low concentrations.

Drinking contaminated water is the most direct route of exposure to pollutants in water. Chemical pollution of sea water could contaminate produced fresh water on the ship. Ships are equipped with desalinating machinery to produce more fresh potable water and use it for showering, drinking and food preparation on the ships. The actual exposure to contamination via 
exposure (methemoglobinemia) and lead exposure (anemia and hypertension). The effects on the developing nervous system can include impaired mental and psychomotor development, as well as cognitive impairment and behavior abnormalities. Chemicals in drinking water can also be carcinogenic (WHO, 2016).

\subsection{Chemical Pollution Monitoring}

The most important in marine oil pollution, expressed by its mass of total leakage, are common, small size pollutions of a few square meters. Invisible size spills do not enter statistics and do not attract the attention of the public media (36\% total mass of oil and related chemicals that may be discharged into the sea) (Satoc, 2005).

Recorded incidents do not include spills if transported in bulk. It is hard to find residues of transparent and dissolving chemicals. It is not possible to see chemical pollution from a ship if the cargo has been transported in bulk.

Statistics research of the incidents brings out a few incidents of chemical spills from ships transporting chemicals in bulk. It was not found the reason of the spill. There are only a few causes of those unknown spills while cargo transported in bulk. It is all deliberately caused by ship's cargo handling (MARDEP, 2001).

Chemical cargo in bulk could be spilled while cargo loading, unloading, handling proper cargo temperatures during voyages and or carrying tank washing residues. It is obvious on the map of Mediterranean Sea, in Fig. 1, that is hard to be on time in next port of call and to clean unloaded tanks on time, due to lack of enough international water areas in whole Mediterranean zone (Bakalar et al., 2011). All shortest routes are through territorial waters. Even if ship's speed is at least 7 knots, as regulated while tank washing, there is no room and no time enough to clean tanks. Cargo operation is a hard job in the ports and at the terminals. Ship's crewmembers work hard all the time during cargo operations and they need resting hours after departures. In the Mediterranean Sea, unloading ports are mostly located in Eastern Mediterranean, and loading ports are in Western Europe for lot of chemical cargo carriers of 2,000 DWT up to 10,000 DWT. It is also lot of bad weather days during those voyages.
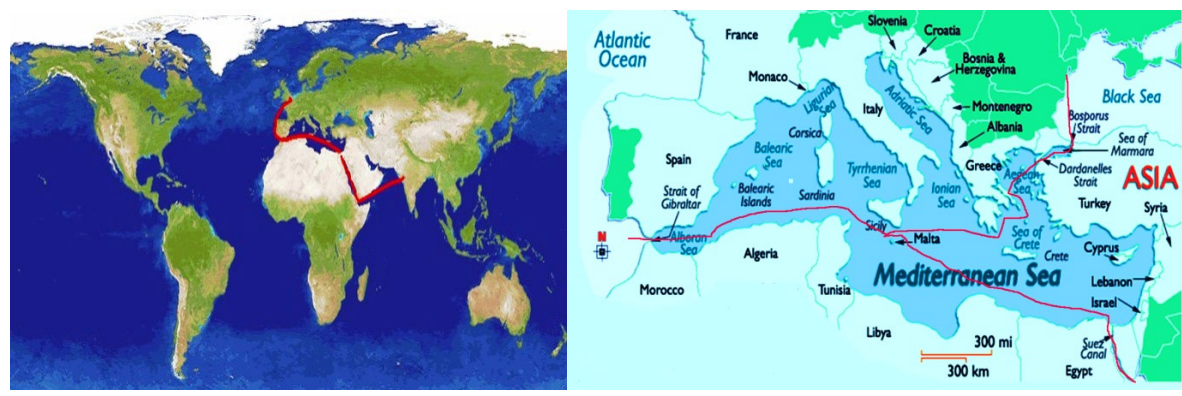

Fig. 1.

Map of the Route from India to North Sea Through Special Area Mediterranean Sea

Source: Modified from (Bakalar, 2013; Bakalar et al., 2011) 
All of those facts show lack of time for tank washing and proper cleaning to make a ship ready for another cargo load in the next port. The time remaining for the part of a voyage in international waters is not always long enough. The Mediterranean had long time been designated a special area under MARPOL Annex V, but it has taken time for the regulations to come into effect due to the lack of disposal facilities in all member states within the area (MARPOL, 1973).

In accordance to MARPOL 73/78 the discharge is made at least 12 miles from the nearest land and not less than 25 meters depth. Ship's speed has to be at least 7 knots. to discharge any residues of tank washing. It is not requested any discharge filtering or monitoring devices. It is allowed not to prewash if in the tanks after unloading remains: any quantity of category A residues, 150 litres and less of category B or 450 litres and less of category $C$ chemical substance residue. No restrictions for category $D$ except the maximum allowed concentration in the wake of the ship is not greater than 1 part of substance in 10 parts of water. That regulation is for tank washing inside special areas, Mediteranean sea too.

The underwater overboard valve for cargo operations still doesn't exist on most of the ships, therefore part of ballast pipe line could be used only. It is usualy used a flexibile hose hanging overboard, connected to ship's cargo pipeline for discharging residues to the sea, as showing in Fig. 2. No any automatic positioning control exists. The race for profit makes this problem even more dangerous to the environment.

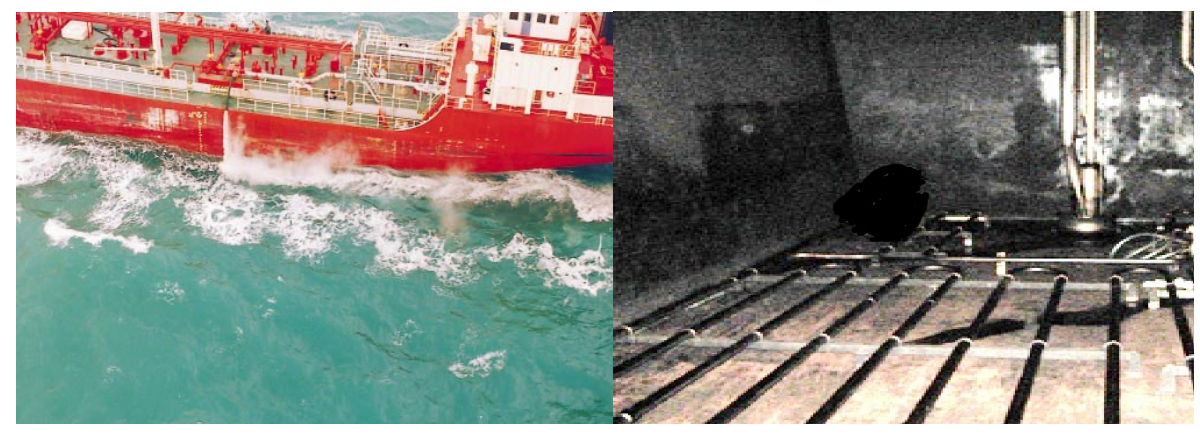

Fig. 2.

Discharge of Tank Washing Residues Overboard into Sea and Bottom of a Cargo Tank with Liquid Cargo Heaters and Deepwell Pump

Source: Modified from (Bakalar et al., 2011)

The way of sea protection and chemical substances pollution prevention is not good enough for big bulk chemical cargo carriers and not good enough for the environment. It is needed new good supervision and monitoring because of the environment and batter health protection. Ships might not be following regulations of tank washing in international waters only, particularly in Mediterranean sea, where not much international waters remain to sail through, while, for example, travelling from eastern Mediterranean to North sea.

In the drums that were found in a few incidents could be either collected defrosted 
crystalized cargo from the ship's pipelines, or collected from overflown tanks during cargo loading operations. It might not be reported if it was not seen by harbour or terminal personnel. Then it could be collected in drums and thrown to the sea. Collection in drums can be, also from residues after unloading was completed, vessel departured and tanks were not washed in international waters. The ship was scheduled for a cargo and was in a hurry to be on time in the next port of call. Therefore, maybe it was no time for voyage extention and tanks were cleaned in coastal waters. The residues of tank cleaning were collected in drums and then thrown into the sea at the point that was decided to be good enough against potentional detection. Lot of drums full of chemicals do not fall overboard so accidentally. Each ship owner or charterer wants his crew to be on time in next port of call, otherwise is risking to await at the anchorage for months to be scheduled again. That is why loyal crew could collect drums aboard a ship, to fill them with chemicals that would be product of unprofessional cargo handling.

Satellite remote monitoring doesn't affect chemical pollution incidents. Chemicals are mostly invisible liquid. The only effective camera monitoring could be monitoring from ship's survelliance systems. Land remote control centre should be able to operate that system remotely using satellite communication advanced technology.

Oil discharge monitor is an operational oil separation and filtering equipment with an automatic stopping device. Monitoring system ensures the most accurate and maintenance free monitoring based on the latest technology and data treatment. It measures the actual oil concentration in water based on light diffusion. The monitoring solutions include interface to Satellite Positioning GPS (Global Positioning System) and computer system, customized user template and possibility for remote service and support. This makes it possible for users to track discharging history for periods of 30 days up to 18 months, as well as other customized features. Oil Discharge Monitor (ODME) consists of the following main parts: computer unit, Zener barrier unit, and analyzing unit.

A computer unit is installed in the cargo control room or in an equivalent nonhazardous area. The computer unit controls and receives data from the other ODME components. This information is treated for computing and control purposes and is stored into a flash memory which could be displayed or printed out an external computer or printer, according to the requirements of the IMO resolutions. The Zener barrier module converts electrical control signals from the computer unit to pneumatic or electrical supply signals for operation of the components that are a part of the ODME equipment. The analyzing unit contains an oil content measuring unit, a dosing pump for sampling, fresh water valve for cleaning purpose, and a pressure monitor that monitors the sample flow. The analyzer determines the oil content in PPM (Part Per Million). A monitor measures the oil content in the sample through advanced light scattering principle. The signals are then processed and through the application of advanced algorithms the displayed oil content disregards virtually all influence of solids present in the sample. The results of the analyzing unit are sent to ship's computer that controlls overboard valve. The device provides two independent alarm contacts, for the operation of an audible alarm and/ 
or operation of an automatic overboard discharge shutdown device (Ship monitoring system, 2016).

This automatic stopping device could be used to prevent chemical substances spill from the ships in coastal area. It is possible to install this monitor in the pumproom of tanker ships equipped with common cargo pumps, not deep well pumps. For tanker ships equipped with deep well pumps an additional solution should be implemented. Alarm purposes should remain unchanged for chemical detection.

\section{A Detection System of Pollution of Hazardous Substances From Ships}

Purpose of following monitoring system is to detect chemicals in sea water used for tank cleaning, and to prevent discharging of that water in protected marine areas.
Parts of the system are, as shown in Fig. 3., satellite communications sub-system, GPS, ship's computer, analyzing software with data filtering ability, and detection sub-system. Detection unit is equipped with flow cytometer which automatically takes samples of sea water, scans them and data are sent to ship's computer. GPS positions of the ship, at the time of pump running and while overboard valves are opened, will feed software of ship's computer which determines whether a ship is in a protected area or not. The positioning data could be supported by needed data from ECDIS (Electronic Chart Display and Information System) that is in use on ships. If the ship is in protected area and flow cytometer detected chemicals in the water, the system will shut off pump and overboard valve. Location for sampling by flow cytometer can be adjusted in depends to ship's size and nature of cargo.

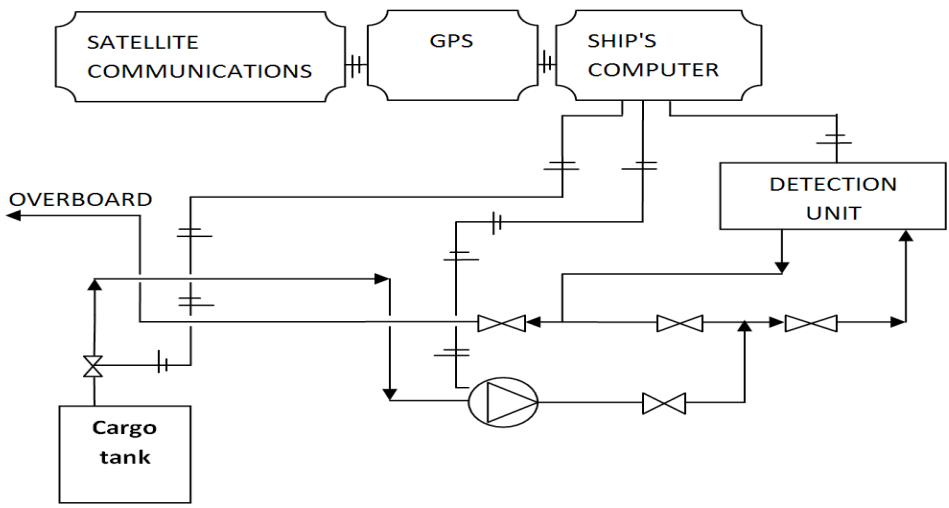

Fig. 3.

Detection System for Preventing Discharge of Liquid Chemicals During Washing of Cargo Tanks

A software used in oil discharge monitor could be modified for use in this flow cytometer detection system. It is needed to change working operational system of anylysing and computer unit in ODME system. The software is already programmed to enable an automatic overboard discharge shutdown and the pump shut off, ordered by 
GPS Satellite positioning system. Instead of controlling the oil ammount, the monitor should control ship's position and chemical content.

An analyse unit of this monitoring system takes spectroscopy metodology where each chemical element has different spectrum. Two chemical elements with identical spectral lines do not exist. That makes this method and system precise and trustfull. That part of this system allows or stops discharge of liquids into the sea, depends to measured detected values (Dobrinić, 2000).

The discharge activity should be automatically stopped if a ship was sailing within 12 miles from any land and if the speed of the ship was not higher than 7 knots and the depth was less than 25 meters. That data should be recorded and followed up by automatically sending an e-mail from ship's computer to more international monitoring institutions such as EMS (Environmental Management System) or local VTS (Vessel Traffic Service) immidiatelly if the ship was breaking the law. This system was suggested as one of patent requests in a patent application done by the first author of this article (Bakalar, 2015).

\section{Discussion}

Importance of this specific pollution has been the objective of many international regulations, but it was not emphasized strong enough to initiate the use of detection technologies (Allan et al., 2006; European Commission, 2006). One of the reasons why oil pollution was solved by using oil discharge monitor is invisibility of chemicals carried as cargo on chemical tankers. Tank washing after cargo has been discharged, is a point of crew overworks. Crew overworks happen when a ship would be late for next cargo due to lack of time for regular ship's operations or due to improper function of ship's equipment (Bakalar, 2012; Bakalar and Baggini, 2016). Result of possible overwork in this case could cause poisoning risk reported in certain research results (Alzieu et al., 1986; Amato et al., 2006, Auman et al., 1998). Monitoring and detection technology used in the system described in this study has been in use in laboratories lately and the ability of the belonging devices was proved (van Der Star et al., 2011; Bakalar, 2012a; Bakalar, 2013). Flow cytometer, as a detection device of automated microscopy, is a sophysticated tool sensitive to working conditions on ships. Reliability of this type of sophisticated systems on ships was calculated in previous certain research and it was $R(t)=$ 0.704688 (Bakalar, 2013). Total reliability of the whole computing subsystem as a part of sensitive electronic systems on board the ships which consists of the two units of which one is software redundant is $R(u)=0.93097$ (Bakalar, 2013).

It has been assumed in previous researches that the computing part of the subsystem in the system with two parallel subsystems, one of which is redundant, will be regularly maintained by operator and by self-diagnosing automatic function errors removal (Bakalar, 2016; Bakalar and Tomas, 2016). In this system, automated functionality covers all sub-systems, so this is an autonomous system. It is just needed to calibrate the flow cytometer to be in accordance with the software and that should be done after each detection by the chief electronic officer (rank on cruise ships) or chief electrician (rank on all cargo and cruise ships). Specific for this pollution is that the ship moves through water and it is almost imposible to take samples from the water 
where the ship has sailed. For harbour waters is not needed this kind of detection because of the possibility to inspect industrial plants (Tanabe, 2008; Sousa et al., 2009; Warner et al., 2010). Remote operation of this system is a goal for the future. Remote operations already exist on ships (Choi et al., 2014; Bakalar and Tomas, 2011; Kim et al., 2014.) and the future of fully autonomous automated remote systems on ships is near. The education and new trainings for crew could make an effect, such it happened with using of some ship's fire equipment (Bakalar, 2011a). High risk of cargo operations, such as tank cleaning, should be diminished with autonomous supervision. A verification of this system for different purpose was done (Bakalar, 2016b; Bakalar and Baggini, 2016a). The working group in GESAMP should be more involved into this problem such as they were very active through the working group for ballast water treatment problems (Bakalar, 2016a; GESAMP, 2001). EMS (Environmental Management System) should exist as a part of immediate response system for this purpose.

\section{Conclusion}

This paper reviews chemical pollution from ships. Tank washing has to be controlled automatically and autonomously. The discharge activity of water with chemicals should be automatically stopped if a ship was sailing within 12 miles from any land and if the speed of the ship was not higher than 7 knots. That has to be controlled and ordered by the use of GPS satellite positioning system, flow cytometer automated microscopy, and could be combined with remote monitoring control from land. The observed data should be followed up by more international institutions immidiatelly if the ship was breaking the law. In that way seas and humans will be protected from ship's chemical cargo pollution.

\section{References}

Allan, I.J.; Vrana, B.; Greenwood, R.; Mills, G.A.; Roig, B.; González, C. 2006. A “toolbox” for biological and chemical monitoring requirements for the European Union's Water Framework Directive, Talanta 69: 302322.

Alzieu, C.; Sanjuan, J.; Deltreil, J.P.; Borel, M. 1986. Tin contamination in Arcachon bay: Effects on oyster shell anomalies, Marine Pollution Bulletin 17(11): 494-498.

Amato, E.; Alcaro, L.; Corsi, I.; Della Torre, C.; Farchi, C.; Focardi, S.; Marino, G.; Tursi, A. 2006. An integrated ecotoxicological approach to assess the effects of pollutants released by unexploded chemical ordnance dumped in the Southern Adriatic (Mediterranean Sea), Marine Biology 149: 17-23.

Auman, H.J.; Ludwig, J.P.; Colborn, T. 1998. Plastic ingestion by Laysan Albatross chicks on Sand Island, Midway Atoll, in 1994 and 1995, In: Robertson G and Gales R (eds). Albatross biology and conservation: 239-244.

Bakalar, G. 2013. Automatic control system for ship ballast water treatment by using flow cytometry and satellite communications technologies, $\mathrm{PhD}$ thesis, 170 p., Rijeka University, Croatia, Available from internet: https://urn.nsk.hr/urn:nbn:hr:187:989679 (Accessed: 25 May, 2016).

Bakalar, G. 2014. Review of interdisciplinary devices for detecting the quality of ship ballast water, SpringerPlus 1(3): 468. DOI: $10.1186 / 2193-1801-3-468$.

Bakalar, G. 2012. A thesis on a remotely controlled BWTS, The Ballast Water Times II, Journal of Institute NIOZ, project NSBWO (North Sea Ballast Water Opportunity) project financed by EU, EK: 3 p. 
Bakalar, G. 2011. Efforts to develop a ballast water detecting device, In Proceedings of Global IMO R\&D Forum on Compliance Monitoring and Enforcement, 117126. Available from internet: http://globallast.imo. org/wp-content/uploads/2015/01/RD_Turkey_2011. pdf (Accessed: 7 September, 2016).

Bakalar, G.; Baggini, M. B. 2016. Automated method and system for monitoring the performance and continuation of ballast water treatment system operation on ships, In Proceedings of 58th International Symposium ELMAR. Available from internet: http://www.elmar-zadar. org/2016/technical_program/program_web_2016_ v8.pdf (Accessed: 5 September, 2016).

Bakalar, G. 2012a. Possibility of Remote Monitoring BWTS Quality, In Proceeding of IMO ICBWM 2012 Globallast R\&D Forum, Singapore.

Bakalar, G. 2015. The System of Remote Control of the Automatic Detection of Ship's Ballast Water via Satellite Communication from Land, Patent app., HR P20150144A.

Bakalar, G.; Tomas, V. 2016. Possibility of Using Flow Cytometry in the Treated Ballast Water Quality Detection, Pomorski zbornik 51(1): 43-55.

Bakalar, G.; Baggini, M. B. 2016a, Automatic communication system ship to shipping terminal, for reporting potential malfunctions of a ballast water treatment system operation, In Proceedings of 39th International Convention MIPRO. DOI: 10.1109/ MIPRO.2016.7522236

Available from internet: http://ieeexplore.ieee.org/ document/7522236/

Bakalar, G. 2016. The system of automatic and autonomous flow and quantity measurement for detection of stoppage of ballast water treatment system operation, Patent app., HR P20160144A.
Bakalar, G.; Tomas, V.; Bukša, A. 2011. Monitoring of chemical pollution from the ships in coastal area, In Procceedings of Abstracts of International Conference on Climate Friendly Transport, Shaping Climate Friendly Transport in Europe, Key Findings \& Future Directions: 41.

Bakalar, G. 2016a. Comparisons of interdisciplinary ballast water treatment systems and operational experiences from ships, SpringerPlus 5(1): 240. DOI: 10.101186/s40064-016-1916-z.

Bakalar, G.; Tomas, V. 2011. Possibility of using satellite communication technologies for remote maintenance in marine industry, 5th GNSS Vulnerabilities and Solutions Conference.

Bakalar, G. 2011a. Intensifying efforts for furthering safety culture in shipping - training aspects, In Proceedings of International conference IMLA 19, 63-70.

Bakalar, G. 2016b. A verification of a remote monitoring results of ballast water management system, In Proceedings of ICTTE Belgrade 2016, 322-327.

Bonn Agreement. 2002. Available from internet $w w w$. bonnagreement.org/eng/html/.../chemical_spills (Accessed: 3 October, 2016.)

Choi, W.J.; Kim, C.H.; Choi, H.M.; Lee, K.S.; Choi, W.J.; Kim, J.M. 2014. Trend Analysis and Diagnosis for BWTS Remote Monitoring, IEMEK Journal of Embeded Systems and Applications 9(3): 127-135.

DOI: 10.14372/MEMEK.014.9.3.127.

Dobrinić, J. 2000. Pollution of Sea by Oil and Elements in Traces, Pomorskizbornik 38 (1): 333-348.

GESAMP. 2001. Protecting the oceans from land-based activities - Land-based sources and activities affecting the quality and uses of the marine, coastal and associated freshwater environment. Rep. Stud. GESAMP No. 71, 162 p. 
European Commission. 2006. EU Marine Strategy. The story behind the strategy. Office for Official Publications of the European Communities, Luxembourg, 32 p.

EEA. 1998. Environmental issue report No 4 Environmental Risk Assessment - Approaches, Experiences and Information Sources from the European Environment Agency (EEA). Available from internet www.eea.europa.eu/publications/GH-07-97-595EN-C2/ (Accessed: 3 October 2016)

Environmental Protection Agency (EPA). 2011. Efficacy of Ballast Water Treatment Systems: a Report by the EPA Science Advisory Board. Available from internet: www. EPA-SAB-11-009-unsigned.pdf. (Accessed 5July, 2016).

Kim, C.H.; Kim, J.M.; Kim, B.C. 2014. Remote Communication of sensor data in Ballast Water Treatment System, The Journal of The Institute of Internet, Broadcasting and Communication 14(6): 139-147.

DOI: $10.7236 / J I I B C .2014 .14 .6 .139$.

MARDEP. 2001. Available from internet http:// www.mardep.gov.hk/en/msnote/pdf/msin 1629.pdf (Accessed: 3 October, 2016.).

MARPOL. 1973. Available from internet http://www. marpoltraining.com/MMSKOREAN/MARPOL/intro/ index.htm (Accessed: 3 October, 2016.).

Ship monitoring system. 2016. Available from internet http://www.nauticexpo.com/prod/deckma-hamburg/ product-30912-268332.html (Accessed 3 October, 2016.).

Roose, R.; Brinkman, U. 2005. Trends in Analogue Chemistry 24:897.
Satoc EU project report. 2005. Available from internet www.satoc.eu/sos/projects/CSeas/reportbits/ report5-3.html (Accessed: 3 October, 2016)

van Der Star, I.; Liebig, V.; Stehouwer, P. P. 2011. The importance of organisms smaller than $10 \mu \mathrm{m}$, In Proceedings of Global R\&D Forum on Ballast Water Management, 41-50.

Available from internet: http://globallast.imo. org/2013/RD_Turkey_2011.pdf(Accessed: 6 February, 2016).

Warner, N.A.; Evenset, A.; Christensen, G.; Gabrielsen, G.W.; Borgå, K.; Leknes, H. 2010. Volatile siloxanes in the European arctic: assessment of sources and spatial distribution, Environmental Science Technology 44(19): 7705-10.

Sousa, A.; Ikemoto, T.; Takahashi, S.; Barroso, C.; Tanabe, S. 2009. Distribution of synthetic organotins and total tin levels in Mytilus galloprovincialis along the 86 Monitoring Chemical Pollution in Europe's Seas: Programmes, Practices and Priorities for Research Portuguese Coast, Marine Pollution Bulletin 58:1130-1138.

Tanabe, S. 2008. Temporal trends of brominated flame retardants in coastal waters of Japan and South China: Retrospective monitoring study using archived samples from es-Bank, Ehime University, Japan, Marine Pollution Bulletin 57:267-274.

WHO, International Programme on Chemical Safety. 2016. Available from internet http://www.who.int/ ipcs/en/ (Accessed: 3 October, 2016.)

\section{ijtte 415}

